\section{IJ§ER}

ISSN: 2149-5939
International Journal of Social Sciences and Education Research

Online, http://dergipark.gov.tr/ijsser

Volume: 3(2), 2017

\title{
Lise öğrencilerinin fizik dersine yönelik umutsuzluk düzeyleri
}

\author{
High school students' hopelessness levels towards physics lesson
}

Tohit Güneş ${ }^{1}$

Fatma Taştan Akdağ2

Received Date: $01 / 09$ / 2016

Accepted Date: 15 / $01 / 2017$

\section{$\ddot{\boldsymbol{O}} \boldsymbol{z}$}

Bu araştırma Lise öğrencilerinin Fizik dersi konusundaki umutsuzluk düzeylerinin çeşitli değişkenler açısından değerlendirilmesi amacıyla yapılmıştır. Çalışma, Samsun il merkezinde yer alan Fen Lisesi, Anadolu Lisesi, Mesleki ve Teknik Anadolu Lisesi'nde öğrenim gören toplam 300 10. Sinıf öğrencisiyle yapılmıştır. Veri toplama aracı olarak umutsuzluk ölçeği ve demografik bilgi formu kullanılmıştır. Elde edilen veriler SPSS-17 paket programı ile değerlendirilmiştir. Araştırma sonuçlarına göre akademik başarı düzeyleri, okul türü, normal ders dişı fizik eğitim durumlarl gibi değişkenlerin farklılıklar oluşturduğu ortaya çıkmıştır. Akademik başarı düzeyinin düşmesine bağlı olarak umutsuzluk düzeylerinin arttı̆ğ görülmüstür. Kızların erkeklerden daha yüksek umutsuzluk düzeyine sahip olduğu ve okul türüne bağlı olarak farklılıklar olduğu saptanmıştır. Okul türlerine bağlı olarak Fizik algılarının değişmesi başarı durumunu etkilemektedir. Öğrencilerin bir derse karşı umutsuzluk düzeylerinin yüksek olması ögrencilerin o dersi başaramamaları sonucunu doğurmaktadır. Bu sonuçlar dikkate alındı̆̆ında ortaöğretim öğrencilerinin Fizik dersine yönelik umutsuzluk düzeylerinin birçok değişkene bağll olduğu görülmektedir.

Anahtar sözcükler: Umutsuzluk düzeyi, Fizik ĕgitimi, Lise öğrencileri

\begin{abstract}
The objective of this study is to research the hopelessness levels of high school students about physics lesson in terms of different variables. The study was conducted on a total of 300 10th grade students studying at Science High School, Anatolian High School, Vocational and Technical Anatolian High School in the city center of Samsun. Hopelessness scale and demographic information form were used as data collection tool. The data obtained were statistically evaluated with Spss-17 package. The results of the study showed that variables such as academic achievement levels, type of school, and state of non-formal education caused differences. Determined that hopelessness levels increased due to the academic achievement level degrees, Girls' hopelessness levels were higher than boys' and there were differences depending on school types. The perception of Physics lesson depends on the type of school and this affects achievement. High levels of students' hopelessness for a lesson causes being unsuccessful in that lesson. Considering these results, high school students' hopelessness level about Physics lesson depends on many variables.
\end{abstract}

Keywords: Hopelessness level, Physics education, High school students

\section{Giriş}

Öğrenme; bireylerin mevcut bilgilerinin dışında yaşam sürecinde yeniden iz bırakan olayların neden olduğu davranış değişikliğidir. Bireyler yeni bilgiyi içselleştirerek bundan sonraki davranışlarında bu bilgi ile hareket etmeye başlarlar. Etkili öğrenmenin gerçekleşebilmesi için öğrencilerin sahip oldukları ön yeterliliklerin gereken düzeyde olması çok önemlidir. Öğrenmenin anlamlı bir şekilde gerçekleşmesi için öğrencilerin öğrenecekleri derse yönelik yeterli düzeyde bilişsel, duyuşsal ve psikomotor becerilere sahip olması gerekmektedir. Bu becerilerin herhangi birindeki eksiklik öğrenmeye engel oluşturmakta ve bu eksiklik öğrencide endişe ve umutsuzluğa

\footnotetext{
${ }^{1}$ Prof. Dr., OMÜ, Eğitim Fakültesi, İlköğretim Bölümü, Samsun/Türkiye, tohitg@,omu.edu.tr

${ }^{2}$ Sorumlu yazar, OMÜ, Eğitim Fakültesi, İlköğretim Bölümü, Samsun/Türkiye, fatmaakdag81@gmail.com
} 
Güneş, T., Taştan Akdağ, F. (2017). Lise öğrencilerinin fizik dersine yönelik umutsuzluk düzeyleri. International Journal of Social Sciences and Education Research, 3(2), 499-507.

yol açmaktadır. Endişe duygusuna sahip ve umutsuzluğa kapılan öğrenci derse katılma ve ders sonrası çalışma konusunda zorlanmakta bu da derse karşı isteksizliği doğurmaktadır. Buna bağlı olarak da öğrencinin başarısı olumsuz yönde etkilenmektedir. O'Connor, Cennery ve Cheyne (2000) e göre, umutsuzluk bireylerin geleceğe yönelik kötümserlik derecesidir. Yenilmez (2010) ise umutsuzluğu bireylerin geleceğe ilişkin olumsuz beklentileridir şeklinde tanımlamıştır. Bu tanımlar dikkate alındığında bir derse yönelik olarak umutsuzluğun dersin başarılıp başarılmayacağına dair inanç oluşturulması olarak tanımlayabiliriz.

Konukbay (2005) a göre umut bireyin problemlerini çözmede güçlü olmasıdır. Yani umut bireyin gelecekle ilgili hedeflerini gerçekleştirme konusunda kendine güvenmesi umutsuzluk ise hedefine hiçbir zaman ulaşamayacağını düşünmesidir. Umutta gelecekteki planların gerçekleşebileceği düşünülürken umutsuzlukta gerçekleşmesi mümkün görülmemektedir (Kılıç \& diğ, 2014). TDK (2016) na göre umut olması beklenilen ya da olacağı düşünülen şey olarak ifade edilirken umutsuzluk ise umudu olmayan, düzeleceği veya iyileşeceği sanılmayan olarak tanımlanmaktadır.

Farklı araştırmacılar (Beck,1971; Durak \& Palabıyıkoğlu, 1994; Abbey, 2006; Kılıç \& ark., 2014) tarafından benzer şekilde tanımlanan umutsuzluk, gerçekçi bir neden olmamasına rağmen bireyin yaşantısındaki deneyimlere yanlış anlamlar yükleyip amacına ulaşmak için hiç çaba sarf etmemesine rağmen olumsuz beklentiler ve olumsuz tutum geliştirmesidir şeklinde ele alınabilir.

Kişilerin başarısızlıklarını içselleştirerek karşılaştıkları sorunları hiçbir zaman çözemeyeceklerine dair inançlarının artması ile yaşantılarına olumsuz anlamlar yükleyerek amaçlarına ulaşmak için çabalamak yerine olumsuz sonuçları beklemeye koyulması umutsuzluk olarak tanımlanmaktadır (Deniz vd., 2007; Kılıç \& ark., 2014).

Umut ile ilgili diğer tanımlamalara bakılacak olursa; Rideout ve Montemuro (1986) umudu kişinin hedeflerine ulaşmada sıfırdan fazla beklentiye sahip olması olarak tanımlarken, Miller (1985) umut kavramını kişinin yaşantısının duygusal ve içsel bir öğesi olarak ifade etmiş, Çelikel ve Erkorkmaz, (2008) ise umudu kişinin geleceğe yönelik olumlu beklentilere sahip olması ve süreçteki zorluklara karşı çaba göstermesini sağlayan bir kavram olarak ifade etmiştir. Yenilmez (2010) umut ve umutsuzluğu birlikte ele almış umutta hedefe ulaşmak için yapılanların başarı getireceğine inancın, umutsuzlukta ise başarısızlığın kabullenildiğini ileri sürmüştür. Benzer şekilde Ehtiyar ve Üngüren, (2009) umutta başarabilme, umutsuzlukta ise inançsızlık ve isteksizlik olduğunu ileri sürmüşlerdir.

Kişinin herhangi bir konudaki başarısı, yaratıc1lığı ve üretkenliği olumlu düşüncelere sahip olması ile başlamaktadır. Kişinin herhangi bir konudaki olumlu düşünceleri başarıya yönelik motivasyonunu arttırarak daha istekli bir şekilde çalışmasını ve hedefe yönelik izleyeceği yolları sağlıklı bir şekilde belirlemesini sağlamaktadır. Olumlu düşünceler kişinin başarısı ve verimliliğini olumlu etkilerken umutsuzluk olumsuz olarak etkilemektedir (Şengül, 2012). Umutsuzluk kişinin sağlığını, hayata bakışını ve bir birey olarak yaşama katkısını olumsuz yönde etkilemektedir (Poch, Villar \& Caparros, 2004; Abela \& Seligman, 2000).

Umutsuzluk kavramı bir bakıma öğrenilmiş çaresizlikten kaynaklanmakta olup bireyin ne yaparsa yapsın başarılı olamayacağı düşüncesinin oluşmasıdır. Başarısız olma düşüncesi öğrencide isteksizliğe ve motivasyonda düşmeye neden olmaktadır. Bireyler çabalarının sonucunda hedef- 
Güneş, T., Taştan Akdağ, F. (2017). High school students' hopelessness levels towards physics lesson. International Journal of Social Sciences and Education Research, 3(2), 499-507.

lerine yönelik olumlu bir sonuca ulaşamayacaklarına dair inanç geliştirdiklerinde öğrenilmiş çaresizlik ortaya çıkmakta ve bunalıma girip başına gelecekleri beklemekte ve depresyona girmektedir (Sutherland \& Singh, 2004; Ulusoy \& Duy, 2013).

Bireylerin yeni bilgileri alması veya sahip olduğu bilgileri kullanması bulunduğu duruma ve gelecekle ilgili beklentilerine bağlı olarak kabul edilmekte (istekli olma, umutlanma gibi) veya reddedilmekte (umutsuzluk, çaresizlik)dir. Dolayısıyla her türlü öğrenmede öğrenenlerin yaşantı düzeneği öğrenme ortamları ve bilginin sunuş biçimi önemli olmaktadır. Şimdiye kadar fen eğitiminde genellikle öğretim yöntem ve teknikleri gibi konular ele alınmış olmasına karşın öğretimde öğrenenlerin psikolojik durumu ile ilgili çalışmalara fazla yer verilmemiştir. Halbuki psikolojik bir durum olan umut ya da umutsuzluğun anlaşılması bilgiyi alma bilgiyi kullanma, başarma ve problem çözme gibi temel fen yeterliliklerinin geliştirilmesine katkı sağlayacaktır. Bu nedenle Fizik dersinin öğrenilmesine karşı öğrencilerin umutsuzluk düzeylerinin başarı, okul durumu Fizik eğitimi ve cinsiyete bağlı olarak nasıl farklılaştığının belirlenmesi amaçlanmıştır.

\section{Yöntem}

Çalışma, Samsun il merkezinde yer alan Fen Lisesi, Anadolu Lisesi, Mesleki ve Teknik Anadolu Lisesi'nde öğrenim gören Fizik dersinin ortak ders olarak okutulduğu 10. Sinıf toplam 300 öğrenciyle yapılmıştır. Veri toplama aracı olarak Beck ve ark. (1971) tarafından geliştirilen ülkemizde bir çok araştırmacı tarafından geçerlilik güvenirlik çalışması yapılan Yenilmez, (2010) tarafından güvenirlik çalışmaları yapılmış 20 maddeden oluşan 'Beck Umutsuzluk Ölçeği' ve demografik bilgi formu kullanılmıştır. Elde edilen veriler SPSS 17 paket programı ile istatistiksel olarak değerlendirilmiştir.

\section{Bulgular}

Çalı̧̧mamızda Fen Lisesi, Anadolu Lisesi, Mesleki ve Teknik Anadolu Lisesi’nde öğrenim gören 10. sınıf öğrencilerine uygulanan umutsuzluk düzeyleri ile ilgili bulgular analiz edilmiş ve aşağıdaki tablolarla ifade edilmiştir.

Aşağıda öğrenci özellikleri ve analiz sonuçlarına göre düzenlenmiş tablo 1 mevcuttur.

Tablo1. Demografik özellikler

\begin{tabular}{|c|c|c|c|}
\hline Demografik Özellikler & & f & $\mathbf{\%}$ \\
\hline \multirow{3}{*}{ Cinsiyet } & Kız & 127 & 42.3 \\
\cline { 2 - 4 } & Erkek & 173 & 57.7 \\
\hline \multirow{3}{*}{ Okul } & Fen Lisesi & 80 & 26.7 \\
\cline { 2 - 4 } & Anadolu Lisesi & 120 & 40.0 \\
\cline { 2 - 4 } & Meslek Lisesi & 100 & 33.3 \\
\hline \multirow{3}{*}{ Fizik Dersi Başarısı } & 0 & 3 & 1 \\
\cline { 2 - 4 } & 1 & 25 & 8.3 \\
\cline { 2 - 4 } & 2 & 66 & 22.0 \\
\cline { 2 - 4 } & 3 & 45 & 15.0 \\
\cline { 2 - 4 } & 4 & 70 & 23.3 \\
\hline Okul Dıșı Fizik Eğitimi & 5 & 91 & 30.3 \\
\cline { 2 - 4 } & Alan & 27 & 9 \\
\cline { 2 - 4 } & Almayan & 273 & 91 \\
\hline
\end{tabular}


Güneş, T., Taştan Akdağ, F. (2017). Lise öğrencilerinin fizik dersine yönelik umutsuzluk düzeyleri. International Journal of Social Sciences and Education Research, 3(2), 499-507.

Tablo1 incelendiğinde; öğrencilerin yaklaşık homojen dağıldığı, okul dışı fizik eğitimi alan öğrencilerin daha az olduğu anlaşılmaktadır. Öğrencilerin notları incelendiğinde öğrencilerin not dağılımlarının 2,4 ve 5 düzeyinde yoğunlaştığı görülmektedir.

Tablo 2. Umutsuzluk düzeyinin genel analizi

\begin{tabular}{|l|c|c|c|c|c|}
\hline & N & Minimum & Maksimum & X & s.s. \\
\hline $\begin{array}{l}\text { Umutsuzluk } \\
\text { Puanı }\end{array}$ & 300 & 0 & 20 & 8.967 & 5.319 \\
\hline
\end{tabular}

Tablo2' ye göre ortaöğretim öğrencilerinin fizik dersine yönelik umutsuzluk düzeyi 20 üzerinden 8.967 ortalama ile genel olarak düşük görünmektedir.

Öğrencilerin fizik dersine yönelik umutsuzluk düzeylerinin demografik özelliklere farklılaşıp farklılaşmadığını belirlemek amacıyla t testi ve varyans analizi sonuçları aşağıda tablolaştırılmıştır.

\subsection{Umutsuzluk düzeyinin okul türüne göre farklllı̆̆l analiz sonuçları}

Tablo 3.a Umutsuzluk düzeyinin okul türüne göre farkl1lı̆̆ puanların betimsel istatistikleri

\begin{tabular}{|c|c|c|c|}
\hline Okul türü & N & X & s.s. \\
\hline Meslek Lisesi & 100 & .51 & .19 \\
\hline Anadolu Lisesi & 120 & .39 & .29 \\
\hline Fen Lisesi & 80 & .44 & .27 \\
\hline
\end{tabular}

Analiz sonuçları öğrencilerin umutsuzluk düzeylerinin okul türüne göre anlamlı bir farklılık olduğunu göstermektedir. $\mathrm{F}(2,297)=5.42, \mathrm{p}<.05$. Okul türü arasındaki farklı1lı̆̆n hangi okullar arasında olduğunu bulmak için yapılan Scheffe testinin sonuçlarına göre Meslek lisesi $(\mathrm{X}=.51)$, Anadolu Lisesi $(X=.39)$ ve Meslek Lisesi $(X=.44)$ olup en yüksek umutsuzluk düzeyi meslek lisesi öğrencilerinindir. En düşük ise Anadolu lisesi öğrencilerinindir.

Tablo 3.b Umutsuzluk düzeyinin okul türüne göre farklılığı analiz sonuçları

\begin{tabular}{|lcccccc|}
\hline Varyansın Kaynağı & K.T. & sd & K.O. & F & p & Fark \\
\hline Gruplararası & .747 & 2 & .374 & 5.421 & .005 & ML-FL \\
Gruplariçi & 20.470 & 297 & .069 & & & ML-AL \\
Toplam & 21.21 & 299 & & & & \\
\hline
\end{tabular}

\subsection{Umutsuzluk düzeyinin fizik başarısına göre farklılı̆̆ı analiz sonuçları}

Tablo 4.a Umutsuzluk düzeyinin fizik başarısına göre farklılığı puanların betimsel istatistikleri

\begin{tabular}{|c|c|c|c|}
\hline Okul Başarısı & N & X & s.s. \\
\hline 0 & 3 & .9 & .086 \\
\hline 1 & 25 & .57 & .225 \\
\hline 2 & 66 & .53 & .216 \\
\hline 3 & 45 & .46 & .244 \\
\hline 4 & 70 & .41 & .275 \\
\hline 5 & 91 & .33 & .266 \\
\hline
\end{tabular}

Öğrencilerin fizik başarısına göre umutsuzluk düzeyi ders notu azaldıkça artmaktadır. $\mathrm{F}(5,294)=8.269$ 
Güneş, T., Taştan Akdağ, F. (2017). High school students' hopelessness levels towards physics lesson. International Journal of Social Sciences and Education Research, 3(2), 499-507.

Tablo 4.b Umutsuzluk düzeyinin fizik başarısına göre farklılık analiz sonuçları

\begin{tabular}{|lccccccc|}
\hline Varyans Kaynağı & K.T. & S.D. & K.O & F & p & Fark \\
\hline Gruplararası & 2.616 & 5 & .523 & 8.269 & .000 & $0-1$ & $0-2$ \\
Gruplariçi & 18.602 & 294 & .063 & & & $0-30-4$ \\
Toplam & 21.218 & & 299 & & & $0-5$ \\
\hline
\end{tabular}

Tablo 5. Umutsuzluk düzeyinin okul dışı fizik eğitimi alma durumuna göre farklılık analizi

\begin{tabular}{|l|l|l|l|l|l|l|}
\hline \multicolumn{2}{|l|}{ Okul dışı fizik eğitimi } & N & X & ss & t & p \\
\hline \multirow{2}{*}{ Umutsuzluk puanı } & Alan & 27 & .40 & .29 & .77 & .442 \\
\cline { 2 - 7 } & Almayan & 273 & .44 & .26 & & \\
\hline
\end{tabular}

Öğrencilerin umutsuzluk düzeylerinin okul dışı fizik eğitimi alma durumlarında bir farklılık görülmemektedir.

Tablo 6. Umutsuzluk düzeyi cinsiyete göre analiz sonuçları

\begin{tabular}{|c|c|c|c|c|c|}
\hline Cinsiyet & $\mathbf{N}$ & $\mathbf{X}$ & ss & $\mathbf{t}$ & $\mathbf{p}$ \\
\hline Kız & 127 & .49 & .27 & 2.89 & .004 \\
\hline Erkek & 173 & .40 & .25 & & \\
\hline
\end{tabular}

İlişkisiz örneklem t testi sonuçlarına göre tablo3 hazırlanmıştır. Kızların umutsuzluk düzeyinin daha yüksek olduğu görülmektedir.

\section{Tartışma}

Öğrenme öğretme sürecinde herhangi bir konunun veya bütünsel olarak bir dersin anlaşılması o derse karşı ilgi ve motivasyona bağlı olarak farklılaşmaktadır. Öğrencilerin başarıya inanmadıkları derslerle ilgili akademik durumları genellikle düşük düzeyde olduğu için o derslerle ilgili algıları da zor ders olarak nitelendirilmektedir. Fizik dersi de ulusal ve uluslararası sinavlarda öğrenci başarının en düşük olduğu derstir. Aynı zamanda ortaöğretim öğrencilerinin okul sınavlarında da en düşük notları alındığı ders olarak yerini korumaktadır. Ulusal sınavlarda Fizik başarısının Fen Lisesi, Anadolu Lisesi ve Meslek lisesi olarak sıralandığı görülmektedir. Bu durum öğrencilerin derse yönelik algılarının ve beklentilerinin farklı okul türlerinde farklılaşabileceği düşüncesini oluşturmaktadır. Çalışmamızda her üç okul türünde öğrencilerin umutsuzluk düzeyi cinsiyet, ders başarısı, okul dışı eğitim ve okul türüne bağlı olarak nasıl değiştiği ortaya konulmuştur.

Yapılan istatistiksel analize göre (Tablo2) her üç okulda öğrenim gören öğrencilerin fizik dersine yönelik umutsuzluk düzeyi 20 üzerinden 8.967 ortalama ile genel olarak düşük görülmektedir. Okul türüne göre umutsuzluk düzeyleri değerlendirildiğinde, en yüksek umutsuzluk düzeyi Meslek lisesi öğrencilerinin, en düşük ise Anadolu lisesi öğrencilerinindir (Tablo 3). Bu durumun nedeni meslek liselerindeki öğrencilerin 10. Sınıf Fizik müfredatını başarabilmek için gereken ön yeterliliklere sahip olmamaları ve buna rağmen aynı müfredat aynı ders kitapları ile derslerin yürütülmeye çalışılması olduğu düşünülmektedir. Bu liselerin başarı durumları ile ilgili yapılan çalışmalarda da buna benzer sonuçlar ortaya çıkmıştır ki bu da genel olarak öğrenci kapasitesi ve ortaöğretim sonrası beklentilere bağlı olarak meydana gelmektedir. (Berberoğlu \& Kalender, 2005). Örneğin Meslek Liselerindeki öğrencilerin ortaöğretim sonrası kariyer planlamalarında Fizikle ilgili beklentileri olmadığı için umutsuzluk düzeyi en yüksek durumdadır. Bu durumun tersine genel anlamda başarılı olan Fen Lisesi öğrencilerinde ise öğrencilere yönelik yüksek başarı 
Güneş, T., Taştan Akdağ, F. (2017). Lise öğrencilerinin fizik dersine yönelik umutsuzluk düzeyleri. International Journal of Social Sciences and Education Research, 3(2), 499-507.

beklentisi ve öğrencilerin geleceğe dair yüksek üniversite hedeflerinde Fiziğin mutlak önemi nedeniyle yetersizlik kaygısından kaynaklanan umutsuzluk düzeyi yüksek çıkmıştır. Bu iki lisenin dışında kalan Anadolu Liselerinde ise ortaöğretim sonrası kariyer planlamaları çok farklı alanlarla ilgili olmasından dolayı sadece Fiziğe bağlı kaygı yüksek oranda olmayacağı düşünülmektedir. Ayrıca başarı ve beklenti açısından Meslek Lisesi ve Fen Liselerine göre daha ortada kalmalarından dolayı umutsuzluk düzeyi de diğer iki liseye göre daha düşüktür. Bu düşüncelere benzer şekilde Özmen ve ark. (2008) na göre geleceğe yönelik kaygıların öğrencileri duygusal açıdan olumsuz etkileyerek umutsuz hissetmelerine neden olacağını ileri sürmüşlerdir.

Farklı kategorilerdeki liselerin Matematik ve Fen derslerine karşı ilgi ve başarı durumları önemli farklılıklar göstermektedir. Başarı durumundaki farklılaşmalar ise umutsuzluk düzeyini doğrudan etkilemektedir (O’Connor, Cennery \& Cheyne, 2000). Çalışmamızda da öğrencilerin fizik başarısına göre umutsuzluk düzeyi değerlendirildiğinde, ders notu arttıkça umutsuzluk düzeyinin azaldığı görülmektedir (Tablo 4). Öğrencilerin bir dersten başarılı olmalarının gelecek beklentilerini olumlu yönde arttırdığı ve dolayısıyla umutsuzluk düzeylerinin düşük olmasına neden olduğu kanısındayız. Öğrencilerin öğrenme ile ilgili bilişsel ve duyuşsal stratejileri önemli olmaktadır. Senemoğlu (1997)'na göre duyuşsal stratejiler, öğrenmede algılama ve motivasyonu arttırarak duygusal engelleri kaldırmaya yardımcı olmaktadır. Özer (2002)'e göre de öğrencilerin duygusal durumlarına göre öğrenmeleri sırasında dikkatini dağınıklığı, olumsuz tutum, sınav kaygısı gibi duyuşsal nitelik taşıyan sorunlarla karşılaştığında öğrenmeleri zorlaşır ve hatta öğrenmeleri mümkün olmayabilir.

Destek olarak okul dışı Fizik eğitimi alan öğrenciler ile sadece okulda Fizik dersi alan öğrenciler karşılaştırıldığında herhangi bir farklılık görülmemektedir (Tablo 5). Farklılık görülmemesinin nedeninin yukarıda da belirtildiği gibi öğrenci kapasitesine ve gelecekle ilgili kariyer planlamalarına bağlı olarak ortaya çıktığı düşünülebilir. Çünkü ek ders alınması zaten sınavlara yönelik ek kazanımlar için yapılmaktadır.

Cinsiyet açısından değerlendirildiğinde kızların umutsuzluk düzeyinin daha yüksek olduğu (Tablo 6) görülmektedir. Bunun hem toplumsal yüklenmeler hem de gelecek kariyer planlamasıyla ilgili olabileceği kanısındayız. Genellikle toplumumuzda kızlara yönelik olarak öğretmenlik, hemşirelik, ebelik veya alan uygulaması olmayan meslekler düşünülmekte ve özellikle mühendislikle ilgili alanlar erkek mesleği olarak görülmektedir. Fizik, Matematik ve diğer fen dersleri daha çok Mühendislik ve Tıp ile ilişkilendirildiği için kız öğrencilerin ilgisini çekmemekte ve dolayısıyla akademik başarılarını düşürmektedir ki bu da umutsuzluk düzeyini arttıran en önemli etkenlerden biridir.

Araştırmamızda elde edilen bulgular genel olarak değerlendirildiğinde öğrencilerin Fizik dersine yönelik umutsuzluk düzeyinin her yönüyle yüksek olduğu görülmektedir. Fizik dersinin içeriği ile ilgili sık sık yapılmakta olan düzenlemelere rağmen her sınıf seviyesinde hala konu yoğunluğu mevcuttur. Konu yoğunluğunun yanı sıra içerik özelliği bakımından Fizik dersi başarılması için iyi derecede matematik bilgisi ve pratiği gerektirmektedir. Fizik dersi her ne kadar fen bilimleri (Fizik, Kimya, Biyoloji) içerisinde değerlendirilse de matematik ile son derece ilişkili bir derstir. Özellikle işlemsel basamakları ve formülasyonları matematiği gerektirdiği için öğrenciler üzerinde iki dersi birden başarma korkusu yaratmaktadır. Yani matematikte başarılı olmadan Fizikte de başarılı olamayacağı kaygısını oluşturduğu kanısındayız. Ayrıca Fizik dersinde başarısız olan öğrencilere bakıldığında büyük bir çoğunluğunun matematik dersinde de başarısız olduğu 
Güneş, T., Taştan Akdağ, F. (2017). High school students' hopelessness levels towards physics lesson. International Journal of Social Sciences and Education Research, 3(2), 499-507.

görülmektedir. Benzer şekilde Çorlu ve ark. (2015) yaptıkları çalışmada fen eğitiminde bireylerin başarılı olmasında iyi derecede matematik bilgisine ihtiyaç duyduklarını belirtmişlerdir.

Fizik dersi yaşamı, evreni anlamayı ve açıklamayı sağlamanın yanı sıra üreten bir toplum olmak için edinilmesi gereken temel bilgilerin kaynağıdır. Bu nedenle öğrencilerinin Fizik dersine karşı umutsuzluk düzeylerinin yüksek olması Fizik disiplinin önündeki en büyük engel olarak görülmektedir. Fizik dersinin formüllerden ve matematikten ibaret olmadığının öğrenciye hissettirilmesinin yanında Kimya ve Biyoloji dersleriyle entegre edilerek ve günlük hayatla ilişkilendirilmesinin önemi göz önünde tutularak, yaparak yaşayarak edinecekleri bilgilerle Fizik dersinin öğrencilere hayatın tam da kendisi olduğunun kavratılması öğretmenlere düşen en önemli görev olarak görülmektedir.

Yukarıda belirtilenlerin dışında umutsuzluğa yol açan diğer faktörlerin de ortadan kaldırılması Fizik öğretimi açısından büyük önem taşımaktadır. Türkiye'de okullardaki fiziki koşullardaki yetersizlikler, ders müfredatlarındaki yoğunluklar, öğretmen yeterliliklerindeki eksiklikler ile birlikte sınavlar dolayısıyla stres ve baskı altındaki öğrencilerin geleceğe dair olumlu beklentiler geliştirmeleri mümkün görülmemektedir. Umutsuzluktan doğan isteksizlikle problemleri çözemeyen, başarabileceğine inanmayan, güdülenemeyen birey kendi amaçlarını belirlemede ve toplumun ihtiyaçlarını karşılamada etkili olamayacaktır (Şengül \& Pınar, 2012).

Sonuç olarak lise türlerindeki farklılıklara rağmen her üç lise türün de de Fizik dersine yönelik umutsuzluk düzeyinin yüksek olduğu görülmektedir. Liseler arasında umutsuzluk düzeyinin farklı olması dikkate alındığında okul türüne bağlı olarak Fizik dersinin işlenişi, müfredatı ve içeriğinin yoğunluk olarak farklılaştırılmasının gerekli olduğu sonucuna ulaşılmıştır. Bu değişiklikler yapılırken programın uygulanma şekli, haftalık ders saati ve derslerin işleniş biçimi dikkate alınarak yapılmalı ve mutlaka günlük yaşama dönük örneklendirmeler ile pratik uygulamalara yer verilmelidir.

\section{Kaynakça}

Abbey, J.G. (2006). Hopelessness at the end of life: The Utility Of The Hopelessness Scale With Terminally Ill Cancer Patients, British Journal of Health Psychology, 11, syf. 173-183.

Abela, J.R.Z. and Seligman, M.E.P. (2000). The Hopelessness Theory of Depression: A Test of the Diathesis-Stress Component in the Inter-Personal and Achievement Domains. Cognitive Therapy and Research, 24(4), 361-378

Beck, A.T., Weissman, A., Lester, D., Trexler, L. (1971). The measurement of pessimism: The hopelessness scale. Journal of Consulting and Clinical Psychology, 12(6), 861-865.

Berberoğlu, G., Kalender, İ. (2005). Öğrenci Başarısının Yıllara, Okul Türlerine, Bölgelere Göre İncelenmesi: Öss ve P1sa Analizi. Journal of Educational Sciences \& Practices, 4(7).

Çelikel, F.Ç. ve Erkorkmaz, Ü. (2008). Üniversite Öğrencilerinde Depresif Belirtiler ve Umutsuzluk Düzeyleri ile İlişkili Etmenler. Nöropsikiyatri Arşivi, 45: 122-9.

Çorlu, S., Capraro, R.M., Çorlu, M. A. (2015). Investigating the Mental Readiness of Pre-service Teachers for Integrated Teaching. International Online Journal of Educational Sciences, 7(1), 17-28.

Deniz, M. E., Hamarta, E., Arslan, C., Başçiftçi, F. (2007). Üniversite Öğrencilerinin Yaşam Doyumu, Umutsuzluk ve Akademik Başarılarının Problem Çözme Yaklaşımları Açısından İncelenmesi, XVI. Ulusal Eğitim Bilimleri Kongresi, 5-7 Eylül 2007, Gaziosmanpaşa Üniversitesi, Tokat.

Durak, A. Palabıyıkoğlu, R. (1994) Beck Umutsuzluk Ölçeği Geçerlilik Çalışması, Kriz Dergisi, 2(2), 311 319. 
Güneş, T., Taştan Akdağ, F. (2017). Lise öğrencilerinin fizik dersine yönelik umutsuzluk düzeyleri. International Journal of Social Sciences and Education Research, 3(2), 499-507.

Kılıç, S., Tektaş, N., Pala, T. (2014). Devlet ve Vakıf Meslek Yüksekokulu Öğrencilerinin Umutsuzluk Düzeylerinin Karşılaştırılması ve Umutsuzluk Düzeylerini Etkileyen Faktörlerin Belirlenmesi. Türkiye Sosyal Araştırmalar Dergisi, 18(2), 169-186.

Konukbay, D. (2005), Engelli Çocuk Ebeveynlerinin Umutsuzluk Düzeyleri ve Problem Çözme Becerileri Arasındaki İlişki, Yüksek Lisans Tezi, Genelkurmay Başkanlığı, Gülhane Askeri Tıp Akademisi, Sağlık Bilimleri Enstitüsü, Ankara.14.

Miller, J.F., 1985. Hope dosent Necessary Spring Eternal Sometimes İt Has To Be Carefully Mined and Channeled. American Journal of Nursing, (85), 22-25.

O’Connor, R.C., Connery, H. and Cheyne, W.M. (2000). Hopelessness: the role of depression, future directed thinking and cognitive vulnerability. Psychology, Health and Medicine, 5(2), 155-162.

Özer, B. (2002). İlköğretim ve Ortä̈ğretim Okullarının Ĕgitim Programlarında Öğrenme Stratejileri. Marmara Üniversitesi Atatürk Eğitim Fakültesi Öğrenme ve Öğretme Birinci Sempozyumu. 29-31

Özmen, D., Dündar, P.E., Çetinkaya, A.Ç., Taşkın, O., Özmen, E. (2008). Lise öğrencilerinde umutsuzluk ve umutsuzluk düzeyini etkileyen etkenler, Anadolu Psikiyatri Dergisi, (9), 8-15.

Poch F.V., Villar E., Caparros B. and ark. (2004). Feelings of Hopelessness in a Spanish University Population. Soc Psychiatry Epidemiol, 39: 326-334.

Rideout, E., Montemuro, M. (1986). Hope, Morale and Adaptation in Patient With Chronic Heart Failure. Journal of Advance Nursing, 11(4); 429-438.

Sutherland, S. K., ve Singh, N.N. (2004). Learned Helplessness and Students with Emotional or Behavioral Disorders: Deprivation in The Classroom. Behavioral Disorders, 29(2), 169-181.

Şengül, S. ve Güner, P. (2012). İlköğretim Matematik Öğretmenliği Programına Devam Eden Öğretmen Adaylarının Umutsuzluk Düzeylerinin Incelenmesi. X. Ulusal Fen Bilimleri ve Matematik Eğitimi Kongresi, Niğde: Niğde Üniversitesi.

TDK. (2016). http://www.tdk.gov.tr (20.07.2016)

Ulusoy, Y., ve Duy, B. (2013). Öğrenilmiş İyimserlik Psiko-eğitim Uygulamasının Öğrenilmiş Çaresizlik ve Akılcı Olmayan İnançlar Üzerindeki Etkisi. Kuram ve Uygulamada Eğitim Bilimleri. Educational Sciences: Theory\& Practice. 13(3);1431-1446.

Yenilmez, K. (2010). Ortaöğretim Öğrencilerinin Matematik Dersine Yönelik Umutsuzluk Düzeyleri. Hacettepe Üniversitesi Ĕ̈itim Fakültesi Dergisi, 38, 307-317.

\section{Extended abstract in English}

The purpose of this study is to assess the hopelessness levels of high school students about physics lesson in terms of different variables. The study was conducted with a total of 30010 th graders studying in Science High School, Anatolian High School and Vocational and Technical High School in the city center of Samsun. The reason why 10th graders were preferred in the study is that physics lesson is thought in this grade commonly in all school types. Hopelessness scale and demographic information form were used as data collection tools. The data were analyzed and assessed with SPSS-17 package program. Our study showed how the hopelessness levels of the students from different school types differed in terms of gender, success in lesson, nonformal education and type of school. According to the statistical analyses, the hopelessness levels of students studying in the three types of schools for physics lesson were found to be low in general with an average of 8.967 out of 20 . When hopelessness levels were assessed in terms of school type, the highest hopelessness levels were found in Vocational and Technical High School students, while the lowest hopelessness levels were found in Anatolian High School students. The reason for this result is thought to be the fact that although students in vocational high schools do 
Güneş, T., Taştan Akdağ, F. (2017). High school students' hopelessness levels towards physics lesson. International Journal of Social Sciences and Education Research, 3(2), 499-507.

not have the prerequisite to be able to succeed in 10th grade physics curriculum, the lessons are taught with the same course books and the same curriculum.

When hopelessness levels were assessed in terms of students' success in physics, it can be seen that hopelessness levels decreased as students' scores increased. We believe that students' being successful in a lesson increases their future expectations positively and thus results in lower hopelessness levels. When students who got non-formal physics education and those who had physics lesson only in school were compared, no differences were found. The reason why there was no difference can be because of students' capacities or their future career planning because students get additional courses to succeed in exams. In terms of gender, female students were found to have higher hopelessness levels. We believe that this may be due to both social loading and future carrier planning. In general, occupations such as teaching, nursing, midwifery or those which do not have field applications are thought to be for girls, while fields especially the ones about engineering are to be male occupations.

When the results of our study were assessed in general, it was found that students had high levels of hopelessness in terms of physics lesson. Having high levels of hopelessness levels for one lesson causes students to be unsuccessful in that lesson. Physics lesson helps to understand and explain the universe, besides being the sources of basic information that one should have in order to be a producing society. Thus, students' having high levels of hopelessness is seen as the biggest barrier for physics discipline. Considering the significance of making students feel that physics is not only about formulas and mathematics and integrating it with chemistry and biology and associating with daily life, the most important duty of teachers is to make students comprehend that physics lesson is the life itself with information they will acquire by experiencing. Despite frequent regulations about the content of physics lesson, there are still too many subjects in each grade. In addition to this, being successful in physics lesson requires a good level of mathematics knowledge and practice in terms of its content. Although physics is assessed within physical sciences (physics, chemistry, biology), it is extremely associated with mathematics. Since its operational steps and formulations requires knowledge of mathematics, it creates a fear of being successful in both lessons on students. That is, students worry that they won't succeed physics if they don't succeed in physics. In addition, it can be seen that a great majority of students who are unsuccessful in physics are also unsuccessful in mathematics.

Eliminating factors that cause hopelessness is of great importance in terms of physics teaching. It does not seem to be possible for students to develop positive future expectations due to insufficient physical conditions of schools, intense curriculums, insufficient teacher proficiencies and the stress and pressure caused by exams.

When the differences in hopelessness levels in terms of high school type were taken into consideration, it was concluded that changes in the teaching of physics lesson, the curriculum and content were necessary. While making these changes, how the program is applied, the weekly hours of class and the way the lesson is taught should be taken into consideration and examples from daily life and practical applications should certainly be included. 